\title{
HUBUNGAN ANTARA CEDERA KEPALA DAN TERJADINYA VERTIGO DI RUMAH SAKIT MUHAMMADIYAH LAMONGAN
}

\author{
Cantik Maharendra Putri ${ }^{1}$, Rahayu$^{2}$, Bragastio Sidharta ${ }^{3}$ \\ Fakultas Kedokteran, Universitas Muhammadiyah Malang \\ J1. Bendungan Sutami No. 188 A Malang, 65145
}

Email : cantikmaharendra1995@gmail.com

\begin{abstract}
ABSTRAK
Vertigo adalah gejala umum yang terjadi pada individu yang mengalami cedera tumpul pada kepala, leher, maupun persimpangan craniocervical. Cedera dapat diakibatkan dari kecelakaan lalu lintas, jatuh dan olahraga. Meningkatnya mobilitas manusia khususnya di kota besar mengakibatkan peningkatan frekuensi kasus cedera kepala yang sering diakibatkan oleh kecelakaan lalu lintas. Angka kejadian vertigo pada pasien cedera kepala berkisar 55\%. Insiden vertigo yang terjadi setelah cedera kepala sekitar 40-60\% biasanya terjadi setelah cedera kepala ringan dan sedang. Tujuan penelitian ini adalah untuk mengetahui hubungan antara cedera kepala dan terjadinya vertigo di Rumah Sakit Muhammadiyah Lamongan. Metode yang digunakan dalam penelitian ini adalah observasional analitik dengan desain penelitian cross sectional. Semua pasien cedera kepala di SMF Bedah Rumah Sakit Muhammadiyah Lamongan periode 1 Januari-31 Desember 2016 yang memenuhi kriteria inklusi dijadikankan sebagai sampel. Data cedera kepala dan vertigo diambil dari rekam medis. Data yang telah diperoleh kemudian dianalisis dan diuji secara statistik dengan menggunakan uji Chi Square. Hasil Uji Chi Square didapatkan hubungan bermakna antara cedera kepala dan vertigo $(\mathrm{p}=0,011)$ sehingga terdapat hubungan antara cedera kepala dan terjadinya vertigo di Rumah Sakit Muhammadiyah Lamongan.
\end{abstract}

Kata Kunci : Cedera kepala, vertigo.

\begin{abstract}
Vertigo is a common symptom that occurs in individuals who have blunt injuries to the head, neck, or craniocervical junction. Injuries can result from traffic accidents, falls and sports. Increased mobility of people especially in large cities resulted in increased frequency of head injury cases that are often caused by traffic accidents. The incidence of vertigo in head injury patients ranged from 55\%. The incidence of vertigo after head injury is about 40-60\% usually occurs after mild and moderate head injury. Objective from this study is to investigate the correlation between bead injury and vertigo in Mubammadiyah Lamongan Hospital. Method applied is analytic observational with cross sectional design. All patients with head injury in Surgery Department Muhammadiyah Lamongan Hospital during 1 January31 December 2016 who complied the inclusion criteria were used as samples. Data of head injury and vertigo were taken from the medical record. Data were obtained then analyzed and tested statistically by using Chi Square test.Cbi Square test results showed a significant relationship between head injury and vertigo $(p=0.011)$, so there was a correlation between head injury and vertigo in Muhammadiyah Lamongan Hospital.
\end{abstract}

Keywords: Head Injury, Vertigo. 


\section{LATAR BELAKANG}

Sistem keseimbangan merupakan sebuah sistem yang penting untuk kehidupan manusia. Sistem keseimbangan membuat manusia mampu menyadari kedudukan terhadap ruangan sekitar. Keseimbangan merupakan sebuah sistem yang saling berintegrasi yaitu sistem visual, vestibular, sistem propioseptik dan cerebelar. Gangguan pada sistem keseimbangan tersebut akan menimbulkan berbagai keluhan, diantaranya berupa sensasi berputar yang sering disebut vertigo.(Ramos ZR et al, 2016)

Vertigo seringkali dinyatakan sebagai rasa pusing, sempoyongan, rasa melayang, badan atau dunia sekelilingnya berputar-putar dan berjungkir balik. Vertigo disebabkan karena alat keseimbangan tubuh tidak dapat menjaga keseimbangan tubuh dengan baik Prevalensi vertigo di Jerman, usia 18 tahun hingga 79 tahun adalah 30\%, 24\% diasumsikan karena kelainan vestibular. Penelitian di Prancis menemukan prevalensi vertigo 48\%.(Grennberg DA, et al, 2013)

Di Indonesia angka kejadian vertigo pada tahun 2012 dari usia 40 sampai 50 tahun sekitar 50\%, yang merupakan keluhan nomor tiga paling sering dikeluhkan oleh penderita yang datang ke praktek umum, setelah nyeri kepala dan stroke Joesoef $A A$ et. al., 2012)

Keluhan vertigo sering muncul pada berbagai kasus yang sering kita jumpai di kehidupan seharihari diantaranya pada kasus cedera kepala ${ }^{[18]}$.Distribusi cedera kepala terutama melibatkan kelompok usia produktif antara 15-55 tahun dan lebih didominasi oleh kaum laki-laki dibandingkan dengan perempuan.(Japardi, 2010)

Prevalensi cedera kepala di Indonesia adalah $8,2 \%$, dengan prevalensi tertinggi ditemukan di Sulawesi Selatan $(12,8 \%)$ dan terendah di Jambi (4,5\%). Perbandingan hasil Riset Kesehatan Dasar / Riskesdas 2007 dengan Riskesdas 2013, menunjukkan kecenderungan peningkatan prevalensi cedera kepala dari 7,5\% menjadi 8,2\%. Jawa Timur menduduki nomor 4 untuk kasus cedera kepala terbanyak $(0,7 \%)$ setelah Papua (1\%), Sumatra Utara $(0,9 \%)$ dan Bangka Belitung (0,8\%).(Badan Penelitian dan Pengembangan Kemenkes, 2013)

Vertigo pasca cedera kepala bisa timbul pasca cedera, beberapa hari atau minggu pasca cedera kepala ringan, sedang maupun berat. Angka kejadian vertigo pada pasien cedera kepala berkisar 55\%. Insiden vertigo yang terjadi setelah cedera kepala sekitar 40-60\% biasanya terjadi setelah cedera kepala ringan dan sedang.(Ramos ZR et al, 2016)

Survei pendahuluan yang dilakukan dari data rekam medik di Rumah Sakit Muhammadiyah Lamongan, didapatkan kasus cedera kepala sebagai kasus yang cukup tinggi dengan jumlah pasien sebanyak 148 orang pada tahun 2016.

\section{TINJAUAN PUSTAKA}

Cedera kepala (trauma capitis) adalah cedera mekanik yang secara langsung atau tidak langsung mengenai kepala yang mengakibatkan luka di kulit kepala, fraktur tulang tengkorak, robekan selaput otak dan kerusakan jaringan otak itu sendiri, serta mengakibatkan gangguan neurologis.(Syabrir H.2012)

Berdasarkan Advenced Trauma Life Support (ATLS) tahun 2004, klasifikasi berdasarkan mekanismenya, cedera kepala dibagi menjadi:

1. Cedera kepala tumpul, biasanya disebabkan oleh kecelakaan kendaraan bermotor, jatuh ataupun terkena pukulan benda tumpul.

2. Cedera kepala tembus, biasanya disebabkan oleh luka tusukan, atau luka tembak. (American College Of Surgeon Commite on Trauma, 2014)

Berdasarkan morfologinya, cedera kepala dapat dibagi menjadi:

1. Fraktur Kranium

Fraktur kranium diklasifikasikan berdasarkan lokasi anatomisnya, dibedakan menjadi fraktur calvaria dan fraktur basis cranii. Berdasarkan keadaan lukanya, dibedakan menjadi fraktur terbuka yaitu fraktur dengan luka tampak telah menembus duramater, dan fraktur tertutup yaitu fraktur dengan fragmen tengkorak yang masih intak.

2. Perdarahan Epidural

Hematom epidural terletak di luar dura tetapi di dalam rongga tengkorak dan gambarannya berbentuk bikonveks atau menyerupai lensa cembung. Biasanya terletak di area temporal atau temporo parietal yang disebabkan oleh robeknya arteri meningea media akibat fraktur tulang tengkorak. 
3. Perdarahan Subdural

Perdarahan subdural lebih sering terjadi daripada perdarahan epidural. Robeknya venavena kecil di permukaan korteks cerebri merupakan penyebab dari perdarahan subdural. Perdarahan ini biasanya menutupi seluruh permukaan hemisfer otak, dan kerusakan otak lebih berat dan prognosisnya jauh lebih buruk bila dibandingkan dengan perdarahan epidural.

4. Contusio dan perdarahan intraserebral

Contusio atau luka memar adalah apabila terjadi kerusakan jaringan subkutan dimana pembuluh darah (kapiler) pecah sehingga darah meresap ke jaringan sekitarnya, kulit tidak rusak, menjadi bengkak dan berwarna merah kebiruan. Luka memar pada otak terjadi apabila otak menekan tengkorak. Contusio cerebri sering terjadi di lobus frontal dan lobus temporal, walaupun dapat juga terjadi pada setiap bagian dari otak. Contusio cerebri dapat terjadi dalam waktu beberapa jam atau hari, berubah menjadi perdarahan intraserebral yang membutuhkan tindakan operasi.

5. Commotio cerebri

Commusio cerebri atau gegar otak merupakan keadaan pingsan yang berlangsung kurang dari 10 menit setelah trauma kepala, yang tidak disertai kerusakan jaringan otak. Pasien mungkin akan mengeluh nyeri kepala, vertigo, mungkin muntah dan pucat.

\section{Fraktur basis cranii}

Hanya suatu cedera kepala yang benarbenar berat yang dapat menimbulkan fraktur pada dasar tengkorak. Penderita biasanya masuk rumah sakit dengan kesadaran yang menurun, bahkan tidak jarang dalam keadaan koma yang dapat berlangsung beberapa hari. Dapat tampak amnesia retrogade dan amnesia pascatraumatik. Gejala tergantung letak frakturnya:

1) Fraktur fossa anterior

Darah keluar beserta likuor serebrospinal dari hidung atau kedua mata dikelilingi lingkaran "biru" (Brill Hematom atan Racoon's Eyes), rusaknya Nervus Olfactorius sehingga terjadi byposmia sampai anosmia.

2) Fraktur fossa media

Darah keluar beserta likuor serebrospinal dari telinga. Fraktur memecahkan arteri carotis interna yang berjalan di dalam sinus cavernous sehingga terjadi hubungan antara darah arteri dan darah vena $(A-V$ shunt). (Sjamsubidajat, 2010)

3) Fraktur fossa posterior

Tampak warna kebiru-biruan di atas mastoid. Getaran fraktur dapat melintas foramen magnum dan merusak medula oblongata sehingga penderita dapat mati seketika.(Ngoerah, 1991)

Penilaian derajat beratnya cedera kepala dapat dilakukan dengan menggunakan Glasgow Coma Scale (GCS) yang diciptakan oleh Jennet dan Teasdale pada tahun 1974. GCS yaitu suatu skala untuk menilai secara kuantitatif tingkat kesadaran seseorang dan kelainan neurologis yang terjadi. Ada 3 aspek yang dinilai yaitu reaksi membuka mata (eye opening), reaksi berbicara (verbal respons), dan reaksi lengan serta tungkai (motor respons).

Cedera kepala diklasifikasikan menjadi 3 kelompok berdasarkan nilai GCS yaitu:

1. Ced

batang otak, Transient Ischemic Attact (TIA) vertebrobasiler, neoplasma, migren basiler, trauma, epilepsi, perdarahan cerebellum, infark batang otak, degenerasi spinoserebelar.

2. Vertigo perifer: disebabkan oleh kelainan di telinga dalam, n.vestibular atau sering disebut primary vestibular disorder, misalnya akibat BPPV pasca trauma, labirintis, meniere's disease, toksin obatobatan seperti streptomisin, neuritis vestibular, tumor di fossa posterior (neuroma akustik), fisiologis (motion sickness), fistula labirin, otitis media, neuritis iskemia akibat diabetes mellitus dan infeksi berpez:(Sjahrir, 2012)

Vertigo pasca cedera kepala dapat terjadi akibat kerusakan telinga bagian dalam, n VIII, vestibular sentral atau adanya kesalahan pilih input sensoris yang dibutuhkan untuk keseimbangan sempurna. Menurut Ashis, Naresh, Khandelwal, Mathuriya dalam jurnal Indian Journal of Neurotrauma tahun 2007, vertigo muncul akibat:

1. Fraktur os. Temporal

Trauma kepala tumpul adalah penyebab utama vertigo pasca trauma, tulang temporal pars petrosa peka terhadap trauma karena sifatnya padat mengandung rongga labirin dan letaknya di dasar tengkorak. Trauma pada telinga dalam dapat atau tidak disertai fraktur tengkorak. 
Fraktur dibagi menadi fraktur longitudinal dan transversal.

a. Fraktur longitudinal merupakan $70-90 \%$ fraktur os. temporalis, terbanyak akibat benturan temporo parietal. Garis fraktur mulai puncak piramid os. petrosus melintang tegmen timpani, menghasilkan deformitas seperti tangga dalam meatus acusticus externus telinga tengah dan mengakibatkan dislokasi rantai tulang pendengaran.

b. Fraktur Transversal merupakan 10-30\% fraktur os. temporal menyilang sumbu panjang piramid os. petrosa dan biasanya akibat benturan oksipital. Garis fraktur menyeberangi fossa posterior ke fossa cranii posterior dan dapat mengenai tulang labirin (bila letaknya lateral) atau merusak MAE yang mengakibatkan kerusakan nervus VII dan nervus VIII (bila letak medial). (Ashis P, et al. 2016)

\section{Commotio Labirin}

Commotio labirin mengakibatkan munculnya gangguan auditori dan vestibuler yang terjadi setelah trauma kepala tumpul tanpa fraktur. Gangguan vestibuler dan auditori terjadi akibat perdarahan mikroskopis koklea dan labirin. BPPV dapat disebabkan oleh commotio labirin atau pengaruh mekanik langsung trauma kepala pada organ otolith, dengan hilangnya otokonia yang meliputi bahan gelatin dan membran otolith. Hasil degenerasi dari otokonia dapat menempati kanalis semiserkularis posterior dan menyebabkan serangan vertigo singkat sehubungan dengan gerakan kepala.(Ashis P, et al. 2016)

3. Perdarahan Epidural, Subdural dan Intraserebral

Pola khas gejala yang mengindikasikan adanya hematom epidural adalah hilangnya kesadaran, diikuti oleh kewaspadaan, kemudian kehilangan kesadaran lagi. Gejala yang paling penting dari hematom epidural adalah: kebingungan, vertigo, mengantuk atau perubahan tingkat kewaspadaan, membesarnya pupil di satu mata, sakit kepala, mual dan muntah. Gejala biasanya terjadi dalam beberapa menit sampai beberapa jam setelah cedera kepala dan menunjukkan situasi yang darurat.(Ashis $P$, et al. 2016)

Hematom subdural paling sering adalah akibat dari cedera kepala berat. Jenis hematom subdural adalah salah satu yang paling mematikan dari semua cedera kepala. Perdarahan mengisi area otak yang sangat cepat, mengompresi jaringan otak. Ini sering mengakibatkan cedera otak dan dapat menyebabkan kematian. Tergantung pada ukuran hematom dan di mana itu menekan pada otak, salah satu gejala berikut akan terjadi: bicara bingung atau tidak jelas, masalah dengan keseimbangan atau berjalan, sakit kepala, vertigo, kejang atau kehilangan kesadaran, mual dan muntah.(Stippler, 2016)

Perdarahan intraserebral dan edema yang menyertainya dapat mengganggu atau mengompresi jaringan otak yang berdekatan, menyebabkan disfungsi neurologis, peningkatan tekanan intrakranial (ICP) dan sindrom herniasi yang fatal.(Biros MH.,2009)

4. Konkusi batang otak atau cedera kompleks saraf VIII Kompleks saraf kedelapan berisiko cedera, bahkan dalam kasus-kasus trauma ringan, karena shearing effect pada zona entri akar saraf ke batang otak.(Benson, et al. 2016)

5. Perdarahan Cerebellum

Salah satu fungsi cerebellum yang utama yaitu mengatur koordinasi gerakan sadar, posisi tubuh dan keseimbangan. Perdarahan pada cerebellum mengakibatkan gangguan fungsi cerebellum, sehingga akan muncul gejala vertigo, disartria dan nistagmus.(Aboe U.G, 2002)

6. Contusio Cerebri

Gerakan deformasi otak pada waktu gerakan kepala yang cepat dan tiba - tiba merupakan mekanisme kerusakan otak akibat cedera kepala tumpul, sehingga menyebabkan bagian viskoelastik otak bergerak dengan rotasi di sekitar sumbu batang otak. Akibatnya, terjadi kerusakan saraf kranial termasuk nervus VIII. Trauma juga menyebabkan kerusakan struktur secara langsung maupun tidak langsung melalui proses iskemia. Gejala klinis contusio cerebri antara lain pusing, sakit kepala, emosi labil, hilangnya atensi dan kemampuan memperoleh informasi menetap dalam beberapa minggu atau bulan dan dapat disertai kelainan neurologi. (Gilroy,2000) 


\section{METODE PENELITIAN}

Desain penelitian ini adalah observasional analitik dengan pendekatan cross sectional. Penelitian dilakukan di bagian rekam medis SMF Bedah Rumah Sakit Muhammadiyah Lamongan. Sampel pada penelitian ini menggunakan total sampling dimana semua pasien cedera kepala ringan, sedang dan berat yang tercatat di Instalasi Rekam Medis Rawat Inap dan Rawat Jalan SMF Bedah Rumah Sakit Muhammadiyah Lamongan pada periode 1 Januari-31 Desember 2016 yang memenuhi kriteria inklusi. Diagnosis cedera kepala dan vertigo diambil dari diagnosis dokter Spesialis Bedah RSM Lamongan.

a. Kriteria Inklusi:

1. Pasien dengan cedera kepala ringan, sedang dan berat yang tercatat dalam rekam medis di Instalasi Rawat Jalan dan Rawat Inap SMF Bedah Rumah Sakit Muhammadiyah Lamongan periode 1 Januari-31 Desember 2016.

2. pasien cedera kepala laki - laki dan perempuan yang berusia 15 - 55 tahun.

b. Kriteria Eksklusi:

1. Pasien dengan riwayat penggunaan obatobatan ototoksik seperti gentamisin, alkohol, riwayat infeksi telinga bagian dalam, riwayat diabetes mellitus, epilepsi, tumor otak, neuroma akustikus, diplopia.

2. Pasien cedera kepala dengan data rekam medis yang diperlukan dalam penelitian tidak lengkap.

Pada penelitian ini dilakukan pengolahan data variabel nominal dan ordinal dengan menggunakan uji Chi Square untuk menganalisis hubungan antara cedera kepala dan terjadinya vertigo.

\section{HASIL DAN PEMBAHASAN}

Analisis statistik dengan uji Chi Square menunjukkan bahwa nilai $p$ yang didapatkan sebesar 0,011 dan taraf signifikansi á $=0,05$. Dengan demikian nilai $p$ yang didapat menunjukkan korelasi yang bermakna antara cedera kepala dengan vertigo karena nilai $p$ kurang dari 0,05 . Hal ini berarti hipotesis nihil / Ho ditolak, sehingga terdapat hubungan cedera kepala dengan vertigo.

Berdasarkan Indian Journal of Neurotrauma tahun 2007, vertigo post cedera kepala merupakan suatu gejala yang muncul setelah cedera kepala ringan, merupakan bagian dari post-concussion syndrome. (Badan Penelitian dan Pengembangan Kemenkes, 2013). Post-concussion syndrome merupakan kumpulan gejala yang terdiri atas nyeri kepala, pusing (dizziness), iritabilitas, mudah lelah, ansietas, gangguan memori yang merupakan sequele setelah cedera kepala ringan tertutup.(Iskandar J, 2010)

Menurut Ashis, Naresh, Khandelwal, Mathuriya dalam jurnal Indian Journal of Neurotrauma tahun 2007, vertigo muncul akibat fraktur tulang temporal, commotio labirin, dan contussio cerebri. Cedera kepala tumpul adalah penyebab utama vertigo pasca cedera yang mengakibatkan dislokasi rantai tulang pendengaran pada fraktur longitudinal dan merusak meatus acusticus eksternus yang mengakibatkan kerusakan nervus VII dan nervus VIII pada fraktur transversal. Commotio cerebri mengakibatkan munculnya gangguan auditori dan vestibuler yang terjadi setelah cedera kepala tumpul tanpa fraktur. Gangguan vestibuler dan auditori terjadi akibat perdarahan mikroskopis koklea dan labirin. Kerusakan saraf kranial termasuk nervus VIII pada contussio cerebri akibat gerakan deformasi otak pada waktu gerakan kepala yang cepat dan tiba-tiba.

\section{KESIMPULAN DAN SARAN}

Kesimpulan dari penelitian ini adalah: Terdapat hubungan antara cedera kepala dan terjadinya vertigo di Rumah Sakit Muhammadiyah Lamongan.

Saran untuk penelitian selanjutnya adalah: hasil penelitian ini belum cukup untuk mengetahui lebih jauh hubungan cedera kepala dengan vertigo pada pasien, terutama untuk mengetahui onset vertigo pada pasien cedera kepala. Sehingga untuk lebih menyempurnakan penelitian diharapkan adanya penelitian lebih jauh untuk mengetahui onset vertigo. Dengan terbuktinya hubungan antara cedera kepala dengan vertigo, diharapkan menjadi sumber pengetahuan bagi masyarakat luas pada umumnya. 


\section{DAFTAR PUSTAKA}

Aboe U.G., Kurnia K., 2002. Neuro-otologi Klinis Vertigo. Surabaya. Airlangga University Press.

American College of Surgeon Committee on Trauma. 2004. Advanced Trauma Life Support for Doctors $7^{\text {th }}$ Ed. 663 N. Saint Clair St, Chicago.

Ashis P, Naresh P, Khandelwal N, et al., 2007. Post Head Injury Vertigo. Indian Journal of Neurotrauma, pp: 33 [online], [diunduh 8 September 2016], tersedia dari http:// www.ncbi.nlm.nih.gov.

Badan Penelitian dan Pengembangan Kesehatan Kementerian Kesehatan RI. 2013. Riset Kesehatan Dasar 2013 (RISKESDAS 2013) [online], [diunduh 12 Februari 2016], tersedia dari www.depkes.go.id/resources/ d o w n l o a d / g e n e r a $1 /$ Hasil\%20Riskesdas\%202013.pdf.

Biros MH, Heegaard WG. 2009. Head injury. In: Marx JA, ed. Rosen's Emergency Medicine: Concepts and Clinical Practice. 7th ed. Philadelphia, PA: Elsevier Mosby: chap 38 [online], [diunduh 10 Agustus 2016].

Brain Injury Association of America. (2006). Types of Brain Injury [online], [diunduh 13 September 2016], tersedia dari: http:// www.biausa.org/pages/type of brain injury.html.

Benson, E Brian MD, Arlen D Meyers. 2016. Posttraumatic Vertigo [online], [diunduh 10 Agustus 2016], tersedia dari: emedicine.medscape.com/article/884361.

George D. 2009. Panduan Praktis Diagnosis \& Tatalaksana Penyakit Saraf. Jakarta. EGC.

Gilroy, John. 2000. Basic of Neurology. Mc Graw Hill Professional.

Greenberg DA, Simon, RP, 2013. Mononeuropatby Simplex. A Lange Medical Book Clinical Neurology. $3^{\text {rd }}$ ed. USA : Appleton Lange; 171.lippincot William \& Wilkins.

Iskandar J. 2010. Penatalaksanaan Cidera Kepala Akut. USU digital library.

Japardi, I, 2010. Cedera Kepala. PT Bhuana Ilmu Populer Kelompok Gramedia, Jakarta.

Joesoef AA, Suryamihardja A, Dewanti et al., 2012. Pedoman Tatalaksana Vertigo, Kelompok Studi Vertigo, PERDOSSI.

Ngoerah, IG, 1991. Dasar-Dasar Ilmu Penyakit Saraf. Airlangga University Press: Surabaya.
Ramos ZR, González, Jiménez M M, et al... 2013. Post concussion syndrome and mild head injury. The role of early diagnosis using Neuropsychological test. spectroscopy [online], [diunduh 20 september 2016], tersedia dari www.pubmed.com

Sjahrir H. 2012. Nyeri Kepala dan Vertigo. Yogyakarta. Pustaka Cendekia Press.

Sjamsuhidajat, Wim de Jong. 2010. Buku Ajar Ilmu Bedah. Jakarta. EGC.

Soemarmo, 2015. Penuntun Neurologi. Tangerang: Binarupa Aksara Publisher.

Stippler M. 2016. Craniocerebral trauma. In: Daroff RB, Jankovic J, Mazziotta JC, Pomeroy SL, eds. Bradley's Neurology in Clinical Practice. 7th ed. Philadelphia, PA: Elsevier;:chap 62 [online], [diunduh 1 September 2016], tersedia dari http://www.ncbi.nlm.nih.gov. 